\title{
DC AND AC CHARACTERISTICS OF GaAs/InGaAs/AIGaAS REAL SPACE TRANSFER TRANSISTORS
}

\author{
H.C. CHEN \\ Department of Electrical Engineering, Far-East Junior College of Technology and \\ Commerce, Tainan, Taiwan 744, Republic of China
}

(Received 17 June, 1996; In final form 30 August, 1997)

\begin{abstract}
$\mathrm{DC}$ and $\mathrm{AC}$ performances of a $\mathrm{GaAs} / \mathrm{InGaAs} / \mathrm{AlGaAs}$ negative resistance field-effect transistor (NERFET) are demonstrated by molecular beam epitaxy (MBE) for the first time. The negative differential resistance (NDR) resulted from the observation of the hot electron real space transfer effect in InGaAs channel. By Hall measurements, the structure shows carrier mobility as high as $4300(13500) \mathrm{cm}^{2} / \mathrm{v}$-s at $300(77) \mathrm{K}$, which is suitable for high frequency operation. For DC performance, the largest peak-to-valley current ratio of the device is about 5 at room temperature. For AC performance, S-parameter measurements of high frequency and microwave characteristics indicate a projected maximum frequency of oscillation of $\mathrm{f}_{\max }=2.7 \mathrm{GHz}$ and a current gain cutoff frequency $\left(\mathrm{f}_{T}\right)$ occurs at $1.8 \mathrm{GHz}$.
\end{abstract}

\section{INTRODUCTION}

Negative resistance field-effect transistors (NERFET) are a three-terminal transistor based on the effect of real space transfer (RST) of hot electrons. ${ }^{1}$ When the heating voltage, $\mathrm{V}_{D S}$, is applied between source and drain electrodes, the emitter electrons are accelerated and become hot. If bias is sufficiently large, electrons may have enough energy to spill over the potential barrier and transfer to the collector (substrate) terminal. The device exhibits an NDR in the source-drain and an efficient control of the injection current by the drain voltage. ${ }^{2-3}$

Recently, most of the efforts have been made on DC characteristics of $\mathrm{AlGaAs} / \mathrm{GaAs}$ structure, ${ }^{4}$ however, the investigation of $\mathrm{AC}$ characteristics are still rare in the literature. Considerable interests have been attracted in 
finding the small-signal circuit and frequency characteristics in order to improve device performance.

In this work, we use GaAs/InGaAs/AlGaAs-based material to characterize the DC and AC performances of RST. The use of InGaAs channel provides potential applications for optoelectronic integrated circuits and high-speed microwave devices in light of its $\Gamma$-to- $\mathrm{L}$ valley separation, high mobility, and large peak electron velocity.

\section{EXPERIMENTAL}

The cross-section of the studied GaAs/InGaAs/AlGaAs RST devices grown by MBE is shown in Fig. 1(a). The substrate was an $\mathrm{n}^{+}$-GaAs layer

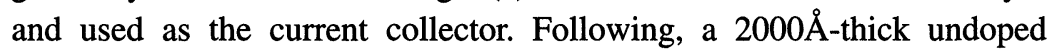
$\mathrm{Al}_{0.45} \mathrm{Ga}_{0.55} \mathrm{As}$ barrier layer was grown. Then, a $100 \AA$-thick pseudomorphic channel, $\mathrm{In}_{0.16} \mathrm{Ga}_{0.84}$ As quantum well, was grown. Finally, an $1800 \AA$-thick $\mathrm{n}^{+}-\mathrm{GaAs}\left(\mathrm{N}_{\mathrm{d}}=2 \times 10^{18} \mathrm{~cm}^{-3}\right)$ cap layer was deposited. The device length (L) between source and drain are $5 \mu \mathrm{m}$. After MBE growth, the isolation regions and the active areas were defined by wet chemical etching using $3 \mathrm{NH}_{4} \mathrm{OH}: 1 \mathrm{H}_{2} \mathrm{O}_{2}: 100 \mathrm{H}_{2} \mathrm{O}$ solution. $\mathrm{Au} / \mathrm{Ge}$ was evaporated onto the cap layer and annealed to form source and drain contacts. I-V characteristics of the RST transistors were measured by HP4145B semiconductor parameter analyzer in the dark.

\section{RESULTS AND DISCUSSION}

Fig. 1(b) shows the energy band diagram of the RST transistor. The Source (or drain) behaves as the hot electron emitter. The third layer, the substrate (collector), is separated by a AlGaAs potential barrier. The substrate current $\left(\mathrm{I}_{s u b}\right)$ as a function of substrate bias $\left(\mathrm{V}_{s u b}\right)$ at $300 \mathrm{~K}$ is shown in Fig.2 with source (or drain) grounded. The $\mathrm{I}_{s u b}$ for $\mathrm{V}_{s u b} \leq 2.5 \mathrm{~V}$ is in the nanoampere range. This shows that the $\mathrm{AlGaAs}$ barrier layer functions properly and the ohmic contacts give low leakage current. On the other hand, from Hall measurements, the proposed structure shows carrier mobilities of $4300 \mathrm{~cm}^{2} / \mathrm{v}$-s at $300 \mathrm{~K}$ and $13500 \mathrm{~cm}^{2} / \mathrm{v}-\mathrm{s}$ at $77 \mathrm{~K}$ with sheet carrier density of 4 and $3 \times 10^{12} \mathrm{~cm}^{-2}$, respectively. These characteristics 


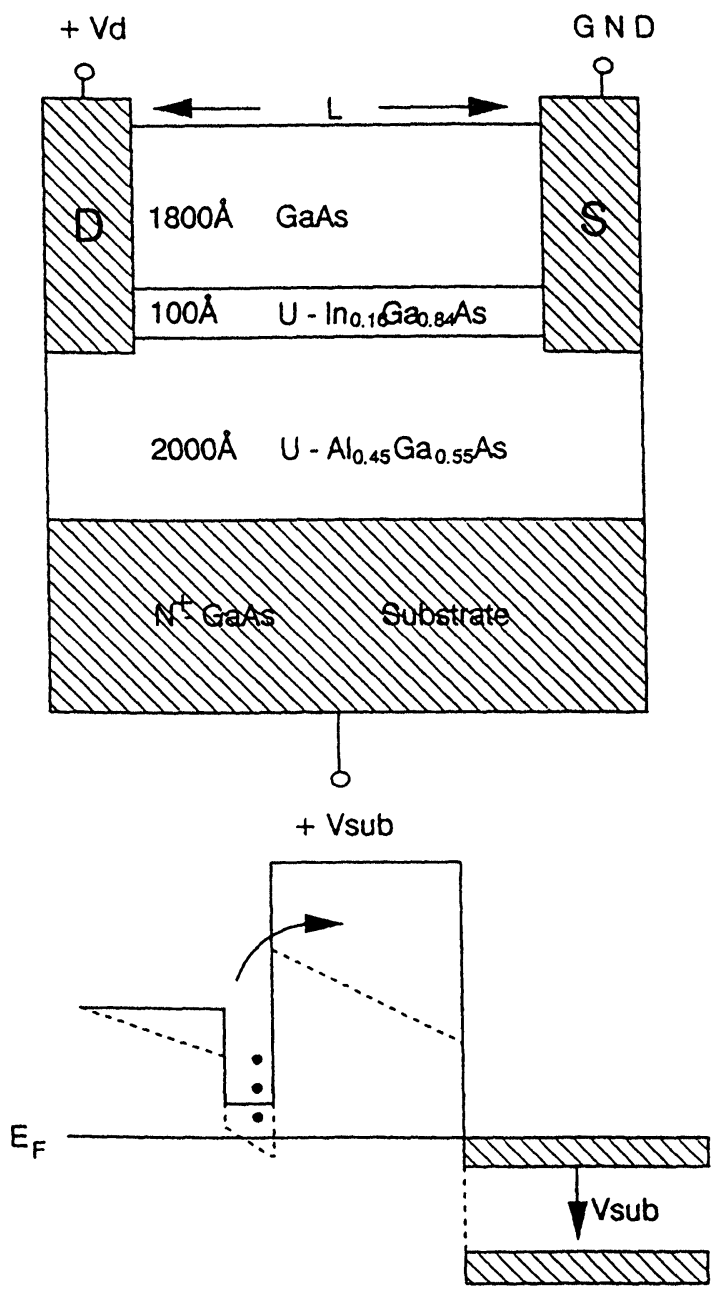

(a)

(b)

FIGURE 1 (a) Schematic cross-section of GaAs/InGaAs/AlGaAs RST transistor (b) Energy band-diagram of the device

show that the structure is suitable for high frequency and high power operations. Fig. 3 shows the drain current $\left(\mathrm{I}_{D}\right)$ under different substrate biases. NDR first occurs at about $\mathrm{V}_{D S}=2 \mathrm{~V}$. In the NDR region, the $\mathrm{I}_{D}$ shows step-like changes with sudden drop in current. This is believed to be due to 


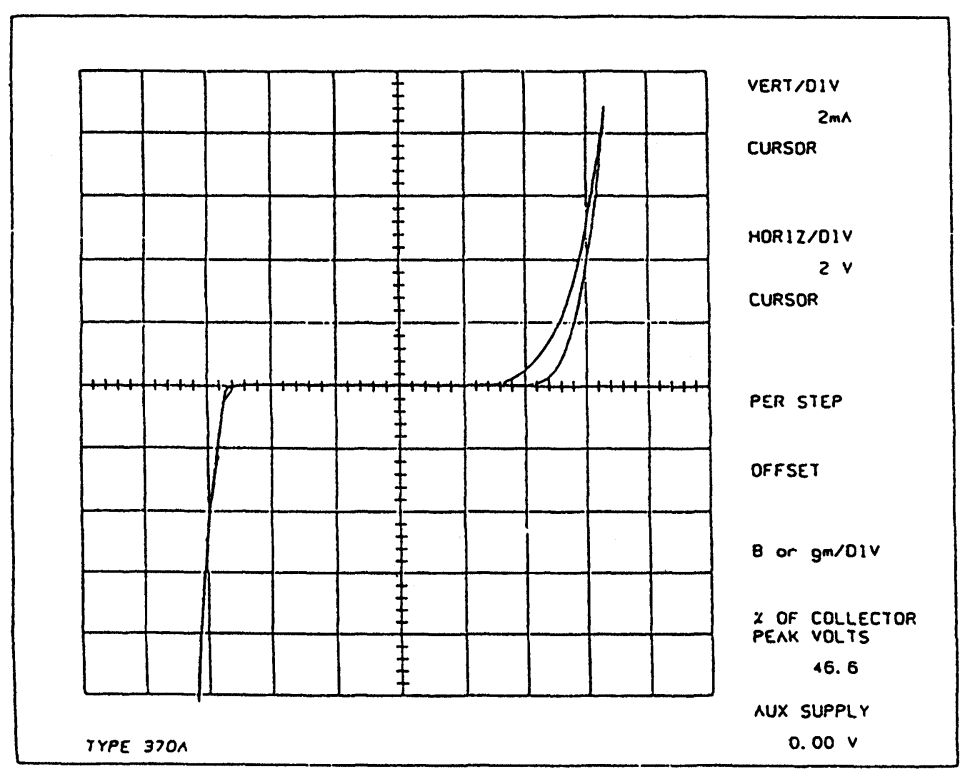

FIGURE $2 \mathrm{I}_{s u b}$ versus $\mathrm{V}_{s u b}$ with source (or drain) grounded. Both polarities are shown

the formation of a positive feedback loop that makes the device switch. The largest peak-to-valley current ratio at $300 \mathrm{~K}$ is about 5 . As the $V_{D S}$ becomes larger than about $12 \mathrm{~V}$, electron flow from the substrate to the drain becomes dominant and the drain current rises. This is the so-called NERFET operation. $\mathrm{I}_{D}-\mathrm{V}_{D S}$ and $\mathrm{I}_{s u b}-\mathrm{V}_{D S}$ characteristics for $\mathrm{V}_{s u b}=8 \mathrm{~V}$ at room temperature are also shown in Fig.4. Fig.4 is also taken at the same condition as in Fig.3. As the $\mathrm{V}_{D S}$ increases, the $\mathrm{I}_{s u b}$ begins to increase with $\mathrm{V}_{D S}$ starting at about $2 \mathrm{~V}$. The large increase in $\mathrm{I}_{s u b}$ indicates a significant transfer of channel electrons. Above $12 \mathrm{~V}$, the $\mathrm{I}_{s u b}$ decreases, which agrees with the increase of $\mathrm{I}_{D}$ shown in Fig.3.

AC characteristics are implemented by on-wafer measurement with low-inductance Microtech Cascade probes and calibration standards. The RST transistors are operated in a common-source configuration with the input signal applied to the drain and the output signal measured from the substrate. All studied RST transistors are measured by a HP87210A network analyzer with the frequency range from $130 \mathrm{MHz}$ to $10 \mathrm{GHz}$ after the standard calibration process is finished. From S-parameter measurements, a projected maximum oscillation frequency $\left(f_{\max }\right)$ of $2.7 \mathrm{GHz}$ and unity current gain cutoff frequency $\left(f_{T}\right)$ of $1.8 \mathrm{GHz}$ are indicated in Fig. 5. The 
ID

$(m A)$

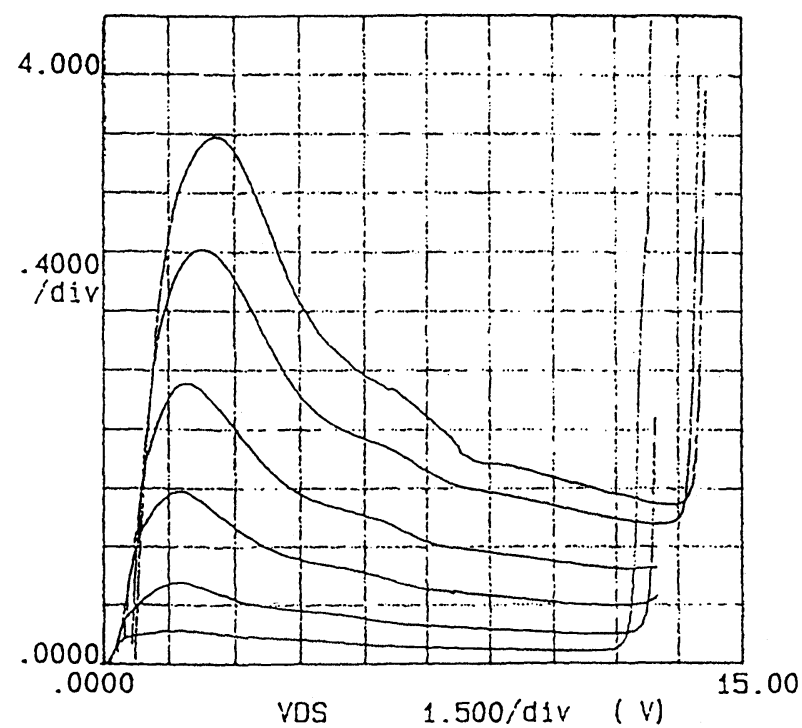

FIGURE $3 \mathrm{I}_{D}$ versus $\mathrm{V}_{D S}$ at room temperature. The source is grounded. Six I-V curves with different biases (the step is $0.5 \mathrm{~V}$ from $\mathrm{V}_{s u b}=7 \mathrm{~V}$ to $9.5 \mathrm{~V}$ ) are shown

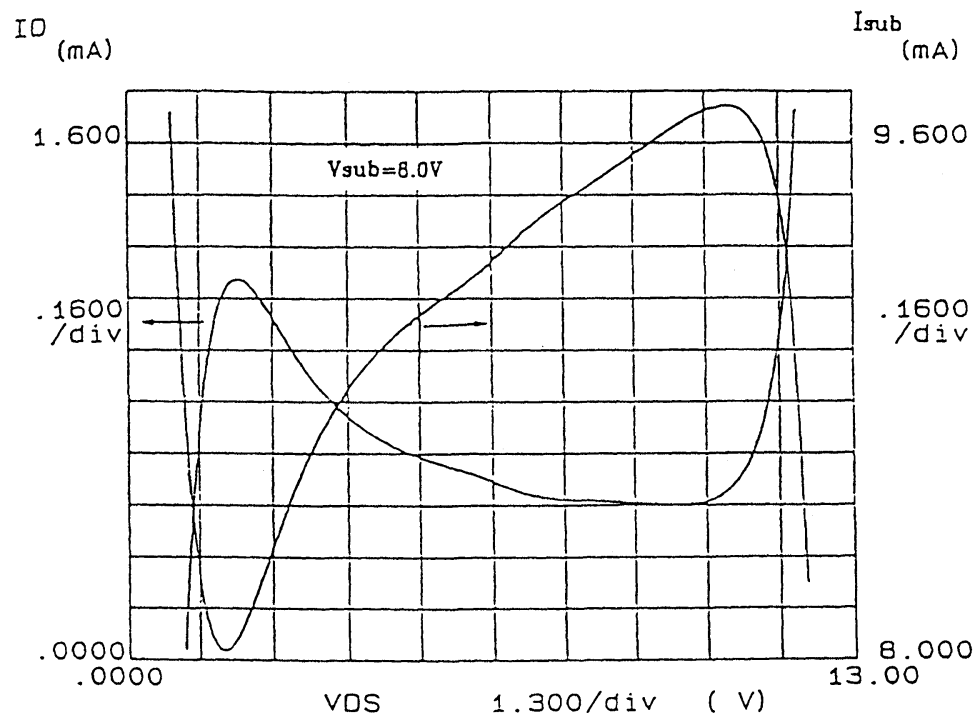

FIGURE $4 \mathrm{I}_{D}$ versus $\mathrm{V}_{D S}$ and $\mathrm{I}_{\text {sub }}$ versus $\mathrm{V}_{D S}$. The source is grounded and $\mathrm{V}_{\text {sub }}=8 \mathrm{~V}$ 
fast decrease in maximum available gain $\left(\mathrm{g}_{\max }\right)$ at frequency above $1.8 \mathrm{GHz}$ is believed to be caused by circuit parasitic loss. On the other hand, $\mathrm{f}_{T}$ and $\mathrm{f}_{\max }$ can be derived from the well-known algebraic transformations of these S-parameters. The experimental data are found to be very consistent with the theoretical analyses as shown in Fig.6.

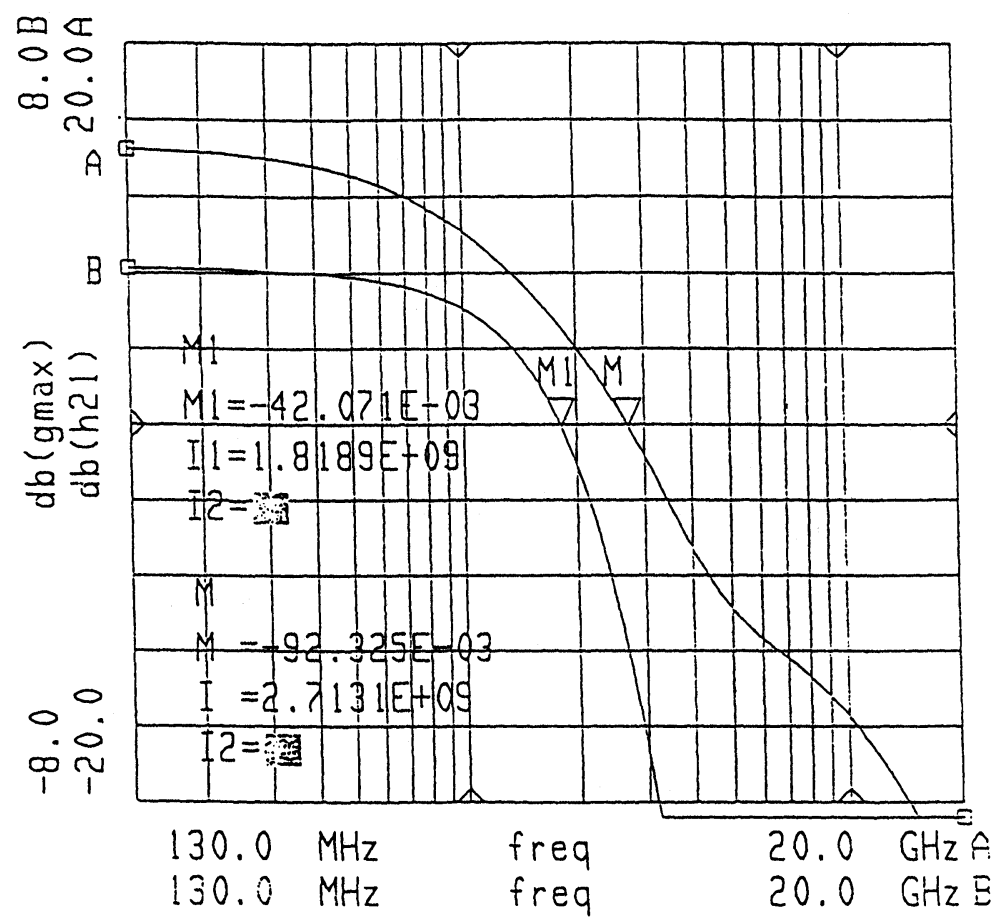

FIGURE 5 Current gain $\left(\mathrm{h}_{21}\right)$ and maximum available gain $\left(\mathrm{g}_{\max }\right)$ versus frequency. $\mathrm{f}_{T}$ and $\mathrm{f}_{\text {max }}$ are extrapolated from this figure

\section{CONCLUSIONS}

RST transistors using GaAs/InGaAs/AlGaAS have been successfully fabricated by MBE. The device shows high carrier mobility (up to 13500 $\mathrm{cm}_{2} / \mathrm{v}$-s) and peak-to-valley current ratio (up to 5) at room temperature. Microwave S-parameter measurements of $f_{T}$ up to $1.8 \mathrm{GHz}$ and $\mathrm{f}_{\text {max }}$ up to $2.7 \mathrm{GHz}$ are obtained for the device length of $5 \mu \mathrm{m}$. Based on these charac- 
dB

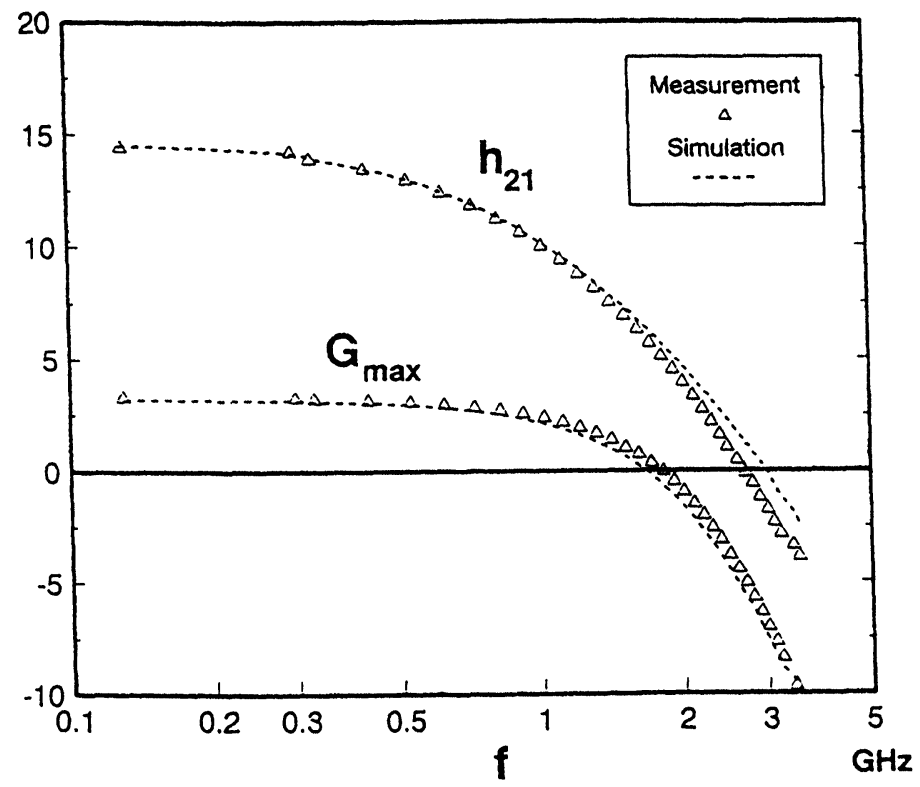

FIGURE 6 Comparison between theoretical analyses and experimental data for the $\mathrm{h}_{21}$ and $\mathrm{g}_{\max }$

teristics, the device has a great feasibility for high-speed and high-power microwave oscillators.

\section{References}

[1] K. Hess, H. Morkoc, H. Shichijo and B.G. Streetman,"Negative differential resistance through real-space electron transfer", Appl. Phys. Lett., 35, 469 (1979)

[2] A. Kastalsky and S. Luryi, "Novel real-space hot-electron transfer devices", IEEE Electron Devices Lett., EDL-4, 334 (1983)

[3] S. Luryi, A. Kastalsky, A.C. Gossard and R.H. Hendel,"Charge injection transfer based on real-space hot-electron transfer", IEEE Trans. Electron Devices, ED-31, 832 (1984)

[4] A.A. Grinberg, A. Kastalsky and S. Luryi," Theory of hot-electron injection in CHINT/NERFET devices", IEEE Trans. Electron Devices, ED-34, 409 (1987) 

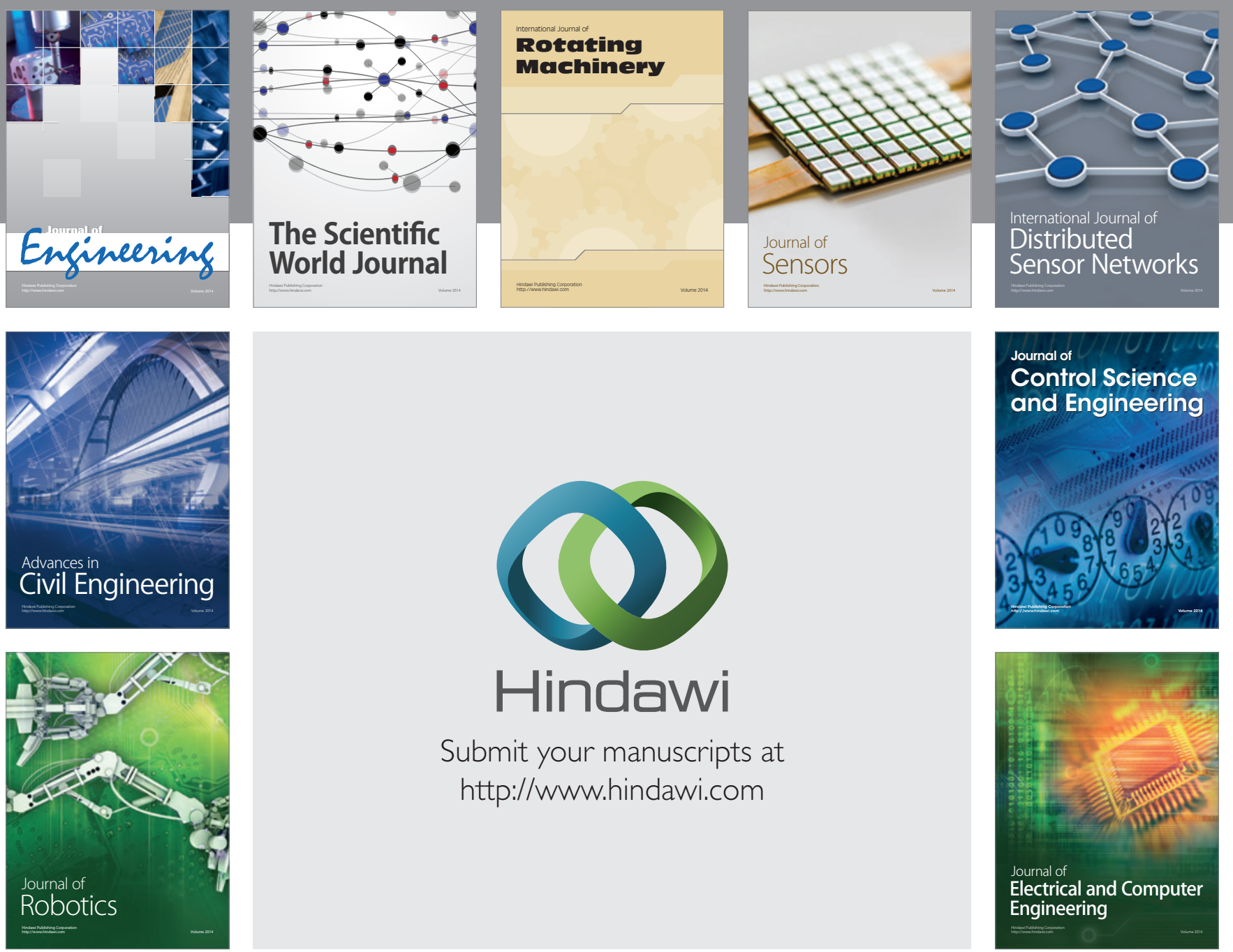

Submit your manuscripts at

http://www.hindawi.com
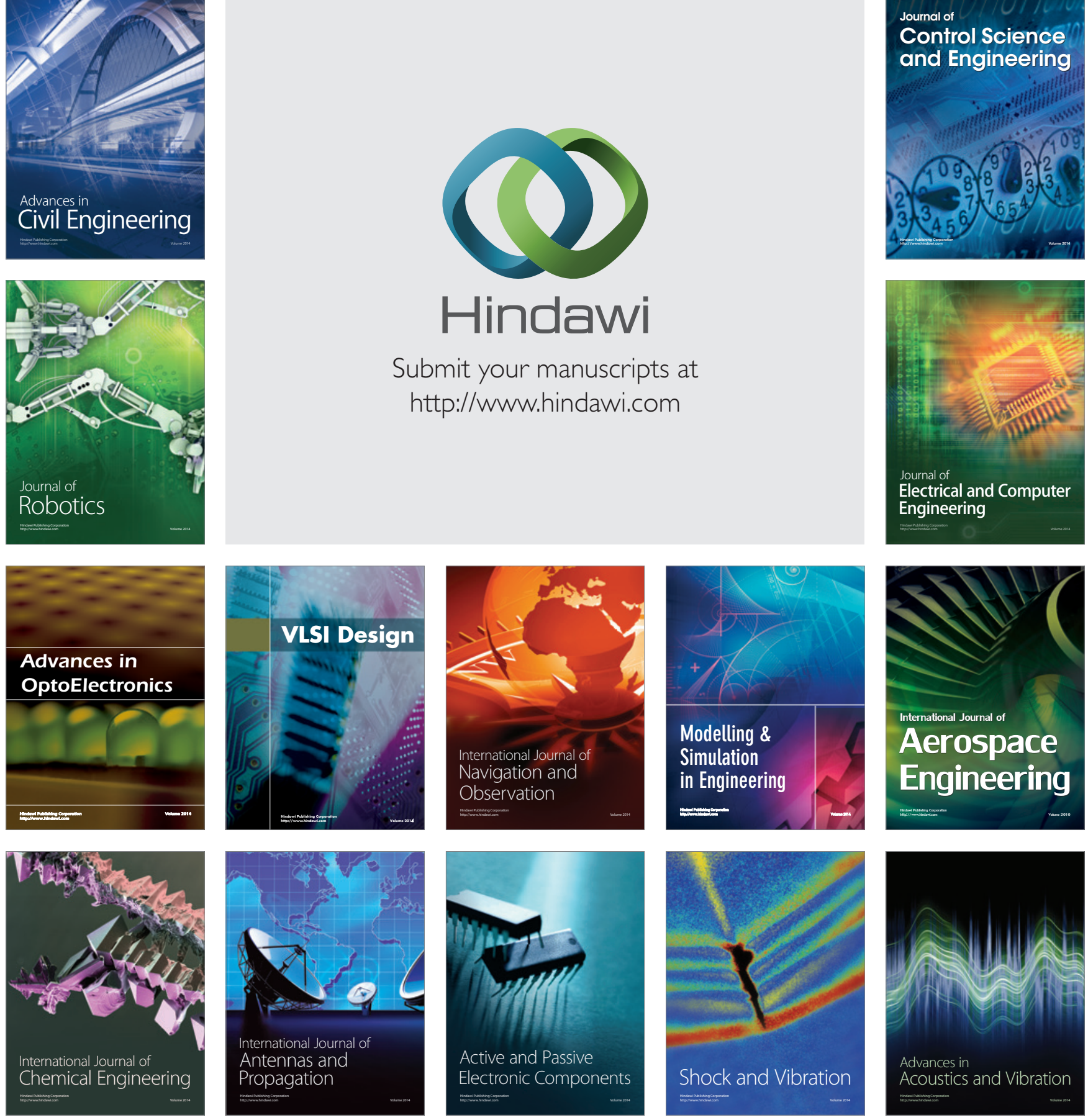